\title{
Direct Determination of Glutathione Reductase in Cells Cultured in Microtitre Plates as a Biomarker for Oxidative Stress
}

\author{
Concepción García-Alfonso, ${ }^{1,3}$, Pilar Sanz ${ }^{1}$, Guillermo Repetto ${ }^{1}$, Manuel \\ Repetto $^{1}$ and Juan López-Barea ${ }^{2}$
}

\author{
${ }^{1}$ National Institute of Toxicology, P.O. Box 863, 41080 Sevilla, Spain; ${ }^{2}$ Departmento de \\ Bioquímica y Biología Molecular, Universidad de Córdoba, Avda de Medina Azahara s/n, \\ 14071 Córdoba, Spain; ${ }^{3}$ Present address: Departamento de Bioquímica y Biología Molecular, \\ Universidad de Córdoba, Avda de Medina Azahara s/n, 14071 Córdoba, Spain
}

\begin{abstract}
Summary - A new method was developed for the direct determination of glutathione reductase (GOR) activity in Vero cells cultured in microtitre plates, avoiding cell-free extract preparation. The cells in each well were washed twice with phosphate-buffered saline, lysed with Triton $\mathrm{X}-100$, and assayed in $0.1 \mathrm{M}$ potassium phosphate, $\mathrm{pH}$ 7.0. After subtracting oxidase activity, which increased with NADPH concentration, the net GOR activity was similar at different oxidised glutathione (GSSG) and NADPH concentrations, thus confirming enzyme saturation. The optimised GOR assay used 2.5mM GSSG and $0.12 \mathrm{mM}$ NADPH; 5mM EDTA was also added to prevent the enzyme from redox inactivation. The GOR activity was directly proportional to the number of cells per well for a wide range of cell densities, thus supporting the assay's validity for use with cultured cells.

The effects on GOR activity of three chemicals which induce oxidative stress, namely, paraquat, iron (II) chloride and iron (III) chloride, were examined to validate the assay under experimental conditions. The specific enzymatic activity increased to $357 \%$ of untreated control activity in $5 \mathrm{mM}$ paraquat-treated cells, and to $407 \%$ of control activity in cells exposed to $7.5 \mathrm{mM}$ iron (II) chloride. By contrast, activity decreased to $56 \%$ of control activity in cells exposed to $5 \mathrm{mM}$ iron (III) chloride. In conclusion, the changes in GOR activity detected in Vero cells confirm that the new assay is suitable for routine in vitro screening of toxicants capable of inducing oxidative stress.
\end{abstract}

Key words: Vero cells, glutathione reductase assay, oxidative stress, paraquat, iron (II), iron (III), biomarker, toxicity.

\section{Introduction}

A variety of environmental pollutants, such as metals, biphenyls and quinones, catalyse the conversion of $\mathrm{O}_{2}$ into reactive oxygen species (ROS), which damage nucleic acids, proteins, lipids and carbohydrates (1-3). Living beings are protected from ROS by antioxidant enzymes, such as superoxide dismutase, catalase, glutathione peroxidase, glutathione reductase, and enzymes that regenerate NADPH. In many cases, the activity of these enzymes is increased under oxidising conditions; additionally, low molecular weight antioxidants, such as vitamins $\mathrm{E}$ and $\mathrm{C}$ or reduced glutathione (GSH), react with ROS and biomolecule-derived radicals $(1,3)$. Oxidative stress results if antioxidant defences are overcome by pro-oxidant agents and ROS are not adequately removed (3). Antioxidant enzymes are used as oxidative stress biomarkers for environmental impact 
assessment $(2,4,5)$.

Glutathione reductase (GOR; 6, 7) is a dimeric pyridine nucleotide:disulphide oxidoreductase containing one FAD molecule per monomer, which catalyses the reaction:

$\mathrm{GSSG}+\mathrm{NADPH}+\mathrm{H}^{+} \rightarrow 2 \mathrm{GSH}+\mathrm{NADP}^{+}$

The oxidised glutathione (GSSG) derives either from direct quenching of oxidants or from detoxification of $\mathrm{H}_{2} \mathrm{O}_{2}$ or organic hydroperoxides through glutathione peroxidases (3). The antioxidative role of GOR has been confirmed in different organisms, since GSH protects the cells from the damage produced by ROS (7).

This study was aimed at adapting and optimising the spectrophotometric assay used with soluble enzyme preparations (6-8) for the determination of GOR activity in cells cultured in microtitre plates. This simplified and rapid assay should obviate the need for preparing cell-free extracts, a step which currently limits the use of this enzymatic activity for testing many samples under different experimental conditions. The established Vero cell line, derived from the kidney of a normal adult African green monkey (9), has been evaluated in this work as a possible alternative to more troublesome primary cell cultures. The effects on GOR activity of the oxidative stress induced by three redox-active compounds, namely, paraquat, and iron (II) and iron (III) ions, in cultured Vero cells, were compared in our study to validate the adapted and optimised GOR assay.

\section{Materials and Methods}

\section{Toxicants and reagents}

Chemicals of the highest purity available were purchased from Sigma (St Louis, MO, USA), and Merck (Darmstadt, Germany).

\section{Cell culture}

The established Vero cell line was a gift from B. Pasamontes and J.M. Gómez, at the Laboratorio de Sanidad y Producción Animal (Córdoba, Spain). The Vero cell line was originally established by T. Yasamura and Y. Kawakita (Chiba University, Chiba, Japan) in 1962 from the kidney of a normal adult African green monkey (Cercopithecus aethiops); the line was submitted to the Animal Cell Culture Collection in the 113th passage and has been prepared and characterised by the American Type Culture Collection (Rockville, MD, USA; 9). Vero cells have a fibroblast-like morphology and were maintained as continuous monolayer cultures in Falcon flasks at $37^{\circ} \mathrm{C}$ in a humidified atmosphere of $5 \% \mathrm{CO}_{2}$ in air. Cells were grown in modified Eagle's medium, supplemented with $10 \%$ fetal bovine serum, $100 \mathrm{U} / \mathrm{ml}$ penicillin $\mathrm{G}$ and $100 \mathrm{mg} / \mathrm{ml}$ streptomycin (Flow Laboratories, Irvine, UK). The viability of plated cells was determined by trypan blue exclusion, as recommended in the repository reference seed stock (9), and in all experiments was higher than $90 \%$.

\section{Toxicant exposure}

Cells were plated in 96-well tissue culture plates (Costar, Cambridge, MA, USA) at a density of 12,000 cells per well and grown as described above. After 24 hours, the culture medium was replaced with $0.2 \mathrm{ml}$ of fresh medium containing the toxicant to be tested and the treated cells incubated for another 24 hours. The compounds were dissolved in sterile water in concentrated form to dilute the culture medium by less than $1 \%$.

\section{Biochemical determinations and cytotoxicity assessment}

All determinations were carried out in the 96-well plates where cell culture and exposure had taken place. Interference of chemicals with the enzymatic activity assays was assayed in parallel.

GOR activity was assayed directly, following NADPH oxidation (8), in 96-well microtitre culture plates as follows: a) culture medium was removed and the cells were washed twice with phosphate-buffered saline (PBS), so only intracellular parameters were determined; b) cells were lysed by incubation with $100 \mu \mathrm{l}$ of $1 \%$ Triton X-100 for 45 minutes at $25^{\circ} \mathrm{C}$; and c) the reagents for enzymatic activity were then added in $100 \mu$ lat concentrations twice those required in the $200 \mu \mathrm{l}$ final reaction mixtures, which contained $0.1 \mathrm{M}$ potassium phosphate buffer (pH 7.0), 5mM EDTA and different concentrations of GSSG $(2.5-10 \mathrm{mM})$ and NADPH $(0.12-0.48 \mathrm{mM})$.

The decrease in NADPH absorbance $(\triangle \mathrm{A})$ was measured at $340 \mathrm{~nm}, 3-10$ minutes after the start of the reaction, with a Titertek Multiscan plate reader (Flow Laboratories, Helsinki, Finland). NADPH oxidation without GSSG (oxidase activity) was determined 
at each reductant concentration and subtracted from the corresponding assays, to give the net GOR activity. The corrected decrease in absorbance was converted into specific enzymatic activity units by considering the NADPH extinction coefficient, the volume and height of the reaction mixture, the time elapsed, and the protein concentration of the sample. One unit of GOR activity was defined as the amount of enzyme transforming one micromole of substrate per minute under the conditions described above.

Protein concentration was determined in situ by adapting the Bradford method (10) to 96-well microtitre plates (11). Plates were washed twice with PBS, and twice again with water to remove the buffer. Then, 100 $\mathrm{\mu l}$ of $0.1 \mathrm{M} \mathrm{NaOH}$ were added to each well and the plates were incubated for 2 hours at $37^{\circ} \mathrm{C}$ to lyse the cells and dissolve the protein. Serial dilutions of bovine serum albumin in $0.1 \mathrm{M}$ $\mathrm{NaOH}$ were used as protein standards. Protein reagent (Bio-Rad Läboratories, Richmond, CA, USA) was added to each well, and the absorbance was read at $620 \mathrm{~nm}$ after 30 minutes.

\section{Effect of cell number on GOR activity}

The effect of cell density on the GOR assay was determined using cells from continuous monolayer cultures after trypsinisation and serial dilutions in PBS. Aliquots $(0.2 \mathrm{ml})$ of each cell dilution were added to the 96 -well tissue culture plates ( 6 wells per concentration). The plates were centrifuged at $880 \mathrm{~g}$ for 7 minutes in an adequate rotor (Sigma, Osterode, Germany). The supernatant was gently aspirated with a multichannel pipette, and the intracellular GOR activity was determined as above.

\section{Statistical analysis}

All experiments were carried out three times, with 6 wells per assay. The statistical significance of the differences in enzymatic activities was determined by one-way analysis of variance (ANOVA; 12). When the data did not fulfil the requirements for the ANOVA test, a non-parametric method, the MannWhitney U-test, was used (13).

\section{Results}

The standard method for GOR assay, in cellfree extracts following NADPH oxidation by
GSSG (6-8), was adapted for the direct assessment of GOR activity in cells grown in microtitre plates, in order to avoid cell-free extract preparation. To check the adapted assay, the GOR activity of a fixed number of cells (12,000 plated per well after 48 hours of growth) was assayed at different substrate concentrations. Figure 1 shows the timecourse of NADPH oxidation with different NADPH and GSSG concentrations; at each NADPH concentration, GSSG was omitted to determine the oxidase activity (upper line of each Figure). As expected, oxidase activity increased with reductant concentration, from a nearly negligible value with $0.12 \mathrm{mM}$ $\mathrm{NADPH}\left(\triangle \mathrm{A}_{\min 3-10}=0.003\right)$, to a low but significant value in the assay with $0.48 \mathrm{mM}$ $\mathrm{NADPH}\left(\triangle \mathrm{A}_{\min 3-10}=0.011\right)$.

The net GOR activity was similar at all substrate concentrations, after oxidase correction: $0.0015 \Delta \mathrm{A} /$ minute was calculated in the assay with $0.12 \mathrm{mM}$ NADPH and $2.5 \mathrm{mM}$ GSSG versus 0.0017 and $0.0016 \Delta \mathrm{A} /$ minute observed in the assays with two-fold and fourfold higher substrate concentrations (Figure 1); thus, even the lower substrate concentrations were saturating. Nevertheless, at high substrate concentrations a lower correlation coefficient was observed, as is shown in Figure 1 by the correlation coefficients of the different assays: $r=0.9981$ with $0.12 \mathrm{mM}$ $\mathrm{NADPH}$ and $2.5 \mathrm{mM}$ GSSG versus $\mathrm{r}=0.9764$ with four-fold higher substrate concentrations. The linearity and saturation of the assay at low substrate concentrations led us to select $2.5 \mathrm{mM}$ GSSG and $0.12 \mathrm{mM}$ NADPH for the standard GOR assay. The GOR assay was not stable for the first 3 minutes after the start of the reaction (not shown); thus, NADPH oxidation was determined between minutes 3 and 10. Finally, 5mM EDTA was also included in the assay to prevent the enzyme becoming inactivated under reducing conditions (7), thus stabilising the enzyme behaviour.

\section{Effects of cell density on GOR activity}

The relationship between GOR (total activity per well) and cell number is shown in Figure 2 . The activity was directly proportional to cell density up to a density of 150,000 cells per well. This wide range includes the density of the cells existing after growth for 48 hours (approximately 35,000 cells per well, due to the proliferation of the 12,000 cells initially plated per well), but the assay could also be 
Figure 1: Time-course of the decrease in NADPH absorbance by the glutathione reductase of Vero cells
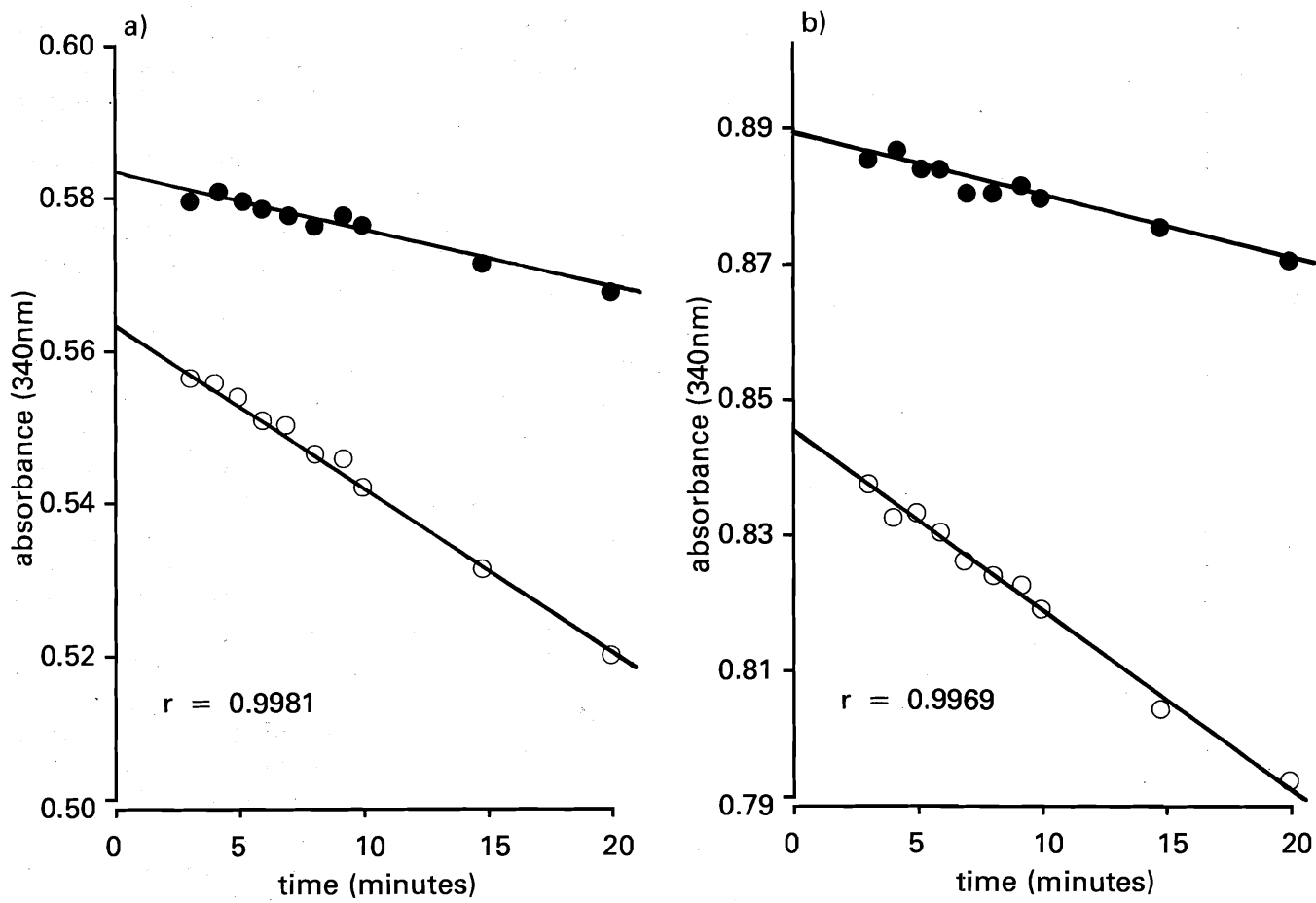

Cells were plated at a density of 12,000 cells per well by adding $0.2 \mathrm{ml}$ of a suspension of 60,000 cells/ml and incubated for 48 hours. Glutathione reductase activity was assayed as described in Materials and Methods in the absence (๑) or presence (O) of oxidised glutathione (GSSG). NADPH and GSSG concentrations were: a) $0.12 \mathrm{mM}$ and $2.5 \mathrm{mM}$, and b) $0.24 \mathrm{mM}$ and $5 \mathrm{mM}$, respectively.

The results show the means of six assays carried out in one representative experiment.

applied to cultures showing much more growth.

\section{Effects of oxidative stress-inducing compounds on GOR activity}

The effects on GOR activity of three chemicals which induce oxidative stress, namely, paraquat, iron (II) chloride and iron (III) chloride $(14,15)$, were examined in Vero cells to validate the optimised assay under experimental conditions. Toxicant concentrations were selected to be close to those yielding a $50 \%$ reduction in cell proliferation (EC50; $5 \mathrm{mM}$ for paraquat [16], 5.5mM for iron (II) chloride and $22 \mathrm{mM}$ for iron (III) chloride [C. GarcíaAlfonso, J. López-Barea, P. Sanz, G. Repetto $\&$ M. Repetto, unpublished data]), in order to detect possible changes in GOR activity in cells healthy enough to respond to the chemical insult. Such a general marker of cytotoxicity was used to avoid more specific viability endpoints related to cell metabolism. However, when $25 \mathrm{mM}$ iron (II) chloride was tested, no GOR activity was detected. Thus a concentration of $5 \mathrm{mM}$ iron (II) chloride was selected.

The GOR activity was compared in untreated cells and cells exposed to $5 \mathrm{mM}$ paraquat, $7.5 \mathrm{mM}$ iron (II) chloride or $5 \mathrm{mM}$ 


\section{Figure 1: continued}

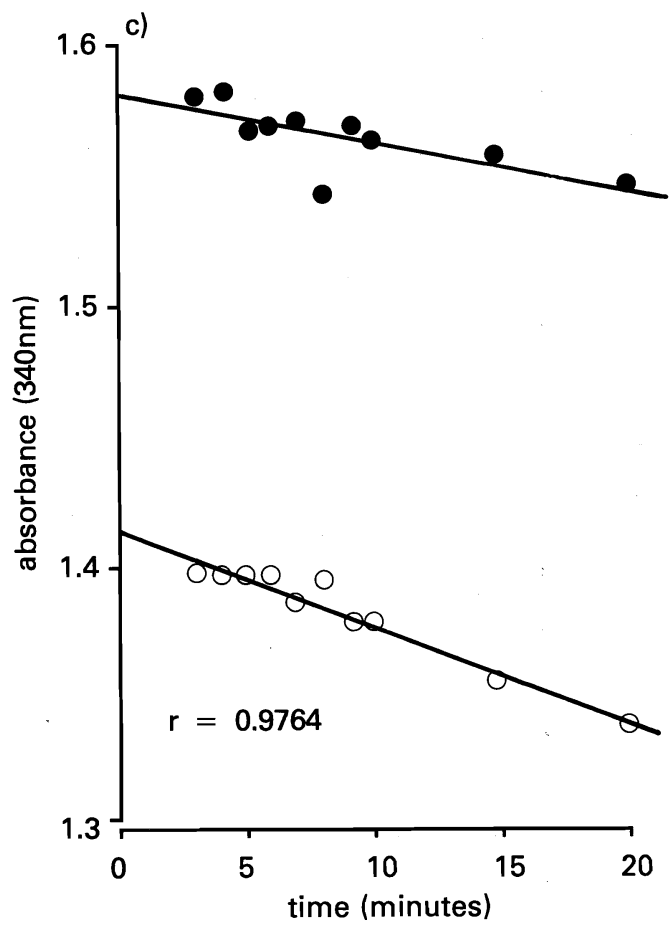

Cells were plated at a density of 12,000 cells per well by adding $0.2 \mathrm{ml}$ of a suspension of 60,000 cells/ml and incubated for 48 hours. Glutathione reductase activity was assayed as described in Materials and Methods in the absence (๑) or presence (O) of oxidised glutathione (GSSG). NADPH and GSSG concentrations were: c) $0.48 \mathrm{mM}$ and $10 \mathrm{mM}$.

The results show the means of six assays carried out in one representative experiment.

iron (III) chloride (Table I). The GOR-specific enzymatic activity increased to $357 \%$ of the activity of the untreated control in paraquattreated cells and to $407 \%$ of control activity in cells exposed to iron (II) chloride. By contrast, GOR activity decreased to $56 \%$ of the control activity in cells exposed to iron (III) chloride. These results indicate that the direct determination of GOR activity in cultured Vero cells could be a useful biomarker for compounds which induce oxidative stress.

\section{Discussion}

Glucose-6-P-dehydrogenase and GOR are involved in the cellular defence against oxidative stress, since they regenerate the NADPH and GSH required to maintain the reduced intracellular redox status (17). In the present study, we intended to develop a method for the direct determination of GOR activity in cells cultured in microtitre plates, to avoid the need to prepare cell-free extracts, and to assess the utility of this enzymatic activity in Vero cells as a possible biomarker of oxidative stress.

As with other pyridine nucleotide-dependent enzymes, GOR displays oxidase activity, and in the absence of GSSG, oxidises NADPH by using $\mathrm{O}_{2}$ as an electron acceptor $(6,7)$. This oxidase activity is deducted from the total GOR activity to give the NADPH oxidation specifically due to GSSG reduction. The effects on GOR and oxidase activities of using several NADPH and GSSG concentrations and different cell densities were initially studied to optimise the standard GOR assay. When the GOR activity of a fixed number of cells was assayed at different substrate concentrations, a time-dependent NADPH oxidation, highly increased by GSSG, was observed in all cases. The GOR activity was similar, after correction, at all GSSG and NADPH concentrations tested, thus indicating that the enzyme was saturated, although the oxidase activities increased at higher NADPH concentrations. The lower correlation coefficient of the assay with high substrate concentrations and the need to avoid substrate inhibition led us to select $0.12 \mathrm{mM}$ NADPH and 2.5mM GSSG for use in the standard GOR assay, in agreement with the conditions previously described for the standard assay of yeast GOR (8). GOR is inactivated under reducing conditions (7), due to the blocking of the reduced enzyme by metal cations such as $\mathrm{Zn}^{2+}$ or $\mathrm{Cd}^{2+}$ (18). Thus, $5 \mathrm{mM}$ EDTA was routinely included to prevent redox inactivation and stabilise the standard assay. Under the conditions previously discussed, the optimised assay showed that GOR activity was directly proportional to the number of cells per well for a wide range of cell densities, supporting its validity for assays with cultured cells.

The toxic effects of three chemicals known to induce oxidative stress $(14,15)$ were analysed as a practical application of the optimised GOR assay in Vero cells cultured in 
Table I: Effect of oxidative stress-inducing compounds on glutathione reductase activity

\begin{tabular}{lcr}
\hline & \multicolumn{2}{c}{ Glutathione reductase activity } \\
\cline { 2 - 3 } Treatment & & \\
(concentration) & mU/mg protein & 100 \\
\hline None & $189 \pm 20$ & 357 \\
Paraquat $(5 \mathrm{mM})$ & $675 \pm 30^{* * *}$ & 407 \\
Iron (II) chloride $(7.5 \mathrm{mM})$ & $769 \pm 130^{* * *}$ & 56 \\
Iron (III) chloride $(5 \mathrm{mM})$ & $105 \pm 10^{* * *}$ & \\
\hline
\end{tabular}

Cells grown for 24 hours were treated for 24 additional hours as indicated, and their glutathione reductase activities and protein concentrations determined.

The results are the means $\pm S D$ of six assays carried out in one representative experiment.

***significant difference from control value at $p<0.001$.

Figure 2: Effects of cell number in the glutathione reductase assay in microtitre plates

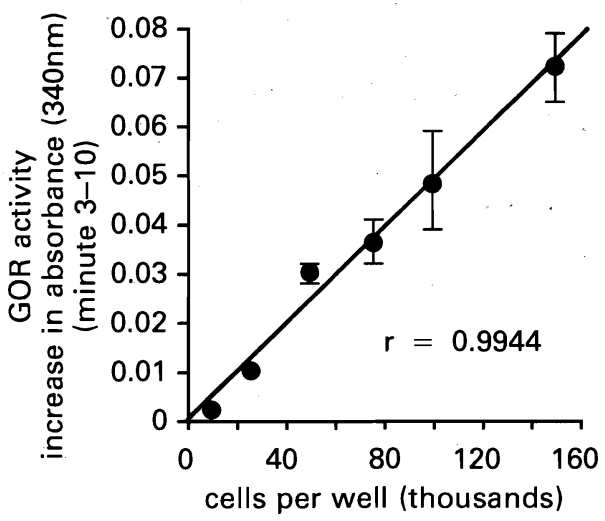

The number of cells indicated were transferred to the 96 -well tissue culture plates, centrifuged, and the glutathione reductase (GOR) activity determined as indicated in Materials and Methods.

Each point represents the mean $\pm S D$ of six replicates carried out in one representative experiment. microtitre plates. The results obtained confirm that GOR is a useful biomarker for detecting the important changes in enzymatic activity produced in response to toxicants inducing oxidative stress. Since the method can be applied to the simultaneous assay of a great number of samples treated under different experimental conditions, it would be a useful tool for screening in vitro the effects of many toxicants in cultured cells.

Paraquat $\left(1,1^{\prime}\right.$-dimethyl-4,4'-bipyridilium dichloride) is a highly toxic herbicide (19), whose bipyridyl ring accepts one electron from NADPH, thus being reduced to the corresponding monocation radical. This derivative subsequently reduces $\mathrm{O}_{2}$ to deleterious ROS, while being reoxidised to its dication form in a "redox cycling" process which promotes oxidative stress $(14,19)$. Similarly, free (non-protein-bound) iron dramatically enhances oxidative stress, by catalysing the conversion of $\mathrm{H}_{2} \mathrm{O}_{2}$ into the highly toxic hydroxyl radical by the Fenton reaction. In this process, iron (II) interacts with $\mathrm{H}_{2} \mathrm{O}_{2}$, yielding an hydroxyl ion and hydroxyl radical, while iron (II) is oxidised to iron (III). Subsequently, the superoxide anion reduces iron (III) to its primitive ferrous state, iron (II), which reinitiates the reaction $(15,20,21)$. 
Oxidative conditions alter the intracellular redox status by oxidising the pools of NADPH/ $\mathrm{NADP}^{+}$and GSH/GSSG $(22,23)$. This is counteracted by increased glucose-6-P-dehydrogenase and GOR activities, mediated by the high $\mathrm{NADP}^{+}$and GSSG concentrations existing under such circumstances (7, 24-26). The increased GOR activity observed in cells exposed to paraquat (3.6-fold) or iron (II) (4.1fold) could be due to short-term or long-term effects. The short-term effects could be attributed to the activation of GOR in response to the oxidised intracellular redox state (24-26). The long-term effects could be due to enhanced expression of the gene encoding for GOR, as previously reported in bacteria for catalase, alkyl-hydroperoxide reductase, endonuclease IV, glucose-6-P-dehydrogenase and superoxide dismutase under oxidative stress $(27,28)$, although this possibility requires further study.

Opposite effects on GOR activity were observed in Vero cells exposed to iron (II) and iron (III), with the reduced form increasing GOR activity four-fold, while the oxidised form decreased this activity by $44 \%$. We have no explanation yet for the decreased GOR activity in iron (III)-exposed cells, since both iron forms readily interconvert in the Fenton reaction (20). Nevertheless, it should be noted that the lipid hydroperoxide-independent initiation of lipid peroxidation by hydroxyl radicals requires chelated iron ions, although only $\mathrm{Fe}^{2+}$-chelate (not the $\mathrm{Fe}^{3+}$ form) promoted lipid peroxidation (29), in analogy to the differential effects of both iron forms on GOR activity.

In conclusion, the GOR assay routinely used for soluble enzyme preparations has been adapted and optimised for the direct assessment of GOR activity in cultured cells. The assay avoids the time-consuming and cumbersome preparation of cell-free extracts, and can be directly applied to cells grown for 48 hours in each well of a microtitre plate. The changes in GOR activity detected in Vero cells exposed to three toxicants, paraquat, iron (II) or iron (III) chloride, confirms that this simple and rapid assay is suitable for the routine in vitro screening of toxicants capable of inducing oxidative stress.

\section{Acknowledgements}

C. García-Alfonso received fellowships from the Consejería de Educación y Ciencia, the
Junta de Andalucía, and the Universidad de Córdoba for her stay in the Instituto Nacional de Toxicología, Sevilla. The authors wish to thank S. Jiménez and M. Gutiérrez for their technical assistance. This work was subsidised by grants to J. López-Barea from CICYT (AMB93-0628-CO2-01) and the Junta de Andalucía (Group 3106).

Received 3.2.95; accepted for publicatin 6.4.95.

\section{References}

1. Sies, H. (1988). Oxidative stress: quinone redox cycling. ISI Atlas of Science: Biochemistry 1, 109 114.

2. Winston, G.W.\& Di Giulio, R.T. (1991). Prooxidant and antioxidant mechanisms in aquatic organisms. Aquatic Toxicology 19, 137-161.

3. Sies, H. (1986). Biochemistry of oxidative stress. Angewandte Chemie International Edition in English 25, 1058-1071.

4. Livingstone, D.R. (1991). Towards a specific index of impact by organic pollution for marine invertebrates. Comparative Biochemistry and Physiology C 100, 151-155.

5. Rodríguez-Ariza, A., Peinado, J., Pueyo, C. \& López-Barea, J. (1993). Biochemical indicators of oxidative stress in fish from polluted littoral areas. Canadian Journal of Fisheries and Aquatic Sciences 50, 2568-2573.

6. Schirmer, R.H., Krauth-Siegel, R.L. \& Schulz, G.E (1989). Glutathione reductase. In Glutathione: Chemical, Biochemical and Medical Aspects, Part $A$ (ed. D. Dolphin, R. Poulson \& O. Avramovic), pp. 553-596. Chichester, UK: John Wiley \& Sons.

7. López-Barea, J., Bárcena, J.A., Bocanegra, J.A., Florindo, J., García-Alfonso, C., López-Ruíz, A., Martínez-Galisteo, E. \& Peinado, J. (1990). Structure, mechanism, functions, and regulatory properties of glutathione reductase. In Glutathione: Metabolism and Physiological Functions (ed. J. Viña), pp. 105-116. Boca Raton, FL, USA: CRC Press.

8. Pinto, M.C., Mata, A.M. \& López-Barea, J. (1984). Reversible inactivation of Saccharomyces cerevisiae glutathione reductase under reducing conditions. Archives of Biochemistry and Biophysics 228, 1-12.

9. Hann, W.D. \& Rhim, J.S. (1974). Vero (Kidney, African Green Monkey, Cercopithecus aethiops). In Flow Manual, pp. 4-45. Irvine, UK: Flow Laboratories Ltd.

10. Bradford, M. (1976). A rapid and sensitive method for the quantification of microgram quantities of protein utilising the principle of protein-dye binding. Analytical Biochemistry 72, 248-254.

11. Repetto, G. \& Sanz, P. (1993). Neutral red uptake, cellular growth and lysosomal function: in vitro effects of 24 metals. ATLA 21, 501-507.

12. Sokal, R.R. \& Rohlf, F.J. (1969). Biometry, 832 pp. New York: Freeman and Company.

13. Siegel, S. (1956). Nonparametric Statistics for the Behavioural Sciences, 258 pp. New York: McGrawHill.

14. Minakata, K., Suzuki, O., Saito, S-I. \& Harada, 
N. (1993). Ascorbate radical levels in human sera and rat plasma intoxicated with paraquat and diquat. Archives of Toxicology 67, 126-130.

15. Miller, D.M., Grover, T.A., Nayini, N. \& Aust, S.D. (1993). Xantine oxidase- and iron-dependent lipid peroxidation. Archives of Biochemistry and Biophysics 301, 1-7.

16. García-Alfonso, C., López-Barea, J., Sanz, P., Repetto, G. \& Repetto, M. (1995). Stimulation of antioxidative enzymes by paraquat in cultured Vero cells. Veterinary and Human Toxiclogy, in press.

17. Liochev, S-I. \& Fridovich, I. (1991). Effects of overproduction of superoxide dismutase on the toxicity of paraquat toward Escherichia coli. Journal of Biological Chemistry 266, 8747-8750.

18. Peinado, J., Florindo, J., García-Alfonso, C., Martínez-Galisteo, E., Llobell, A. \& López-Barea, J. (1991). Metals are directly involved in the redox interconversion of Saccharomyces cerevisiae glutathione reductase. Molecular and Cellular Biochemistry 101, 175-187.

19. Bus, J.S., Aust, S.D. \& Gibson, J.E. (1977). Lipid peroxidation as a proposed mechanism for paraquat toxicity. In Biochemical Mechanism of Paraquat Toxicity (ed. A.P. Autor), pp. 157-174. London: Academic Press.

20. Halliwell, B. \& Gutteridge, J.M.C. (1991). Role of free radicals and catalytic metal ions in human disease: an overview. Methods in Enzymology 186, $1-85$.

21. Zager, R.A., Schimpf, B.A., Bredl, C.R. \& Gmur, D.J. (1993). Inorganic iron effects on in vitro hypoxic proximal renal tubular cell injury. Journal of Clinical Investigation 91, 702-708.
22. Brigelius, R. (1985). Mixed disulfides: biological functions and increases in oxidative stress. In Oxidative Stress (ed. H. Sies), pp. 243-272. London: Academic Press.

23. Masanet, J., Gómez-Lechón, M.J. \& Castell, J.V. (1988). Hepatic toxicity of paraquat in primary cultures of rat hepatocytes. Toxicology in Vitro $\mathbf{2}$, 275-282.

24. Llobell, A., López-Ruíz, A., Peinado, J. \& LópezBarea, J. (1988). Glutathione reductase directly mediates the stimulation of yeast glucose-6phosphate dehydrogenase by GSSG. Biochemical Journal 249, 293-296.

25. Peinado, J., Florindo, J. \& López-Barea, J. (1992). Glutathione reductase from Saccharomyces cerevisiae undergoes redox interconversion in situ and in vivo. Molecular and Cellular Biochemistry 110, 135-143.

26. García-Alfonso, C., Martínez-Galisteo, E., Llobell, A., Bárcena, J.A. \& López-Barea, J. (1993). Regulation of horse-liver glutathione reductase. International Journal of Biochemistry 25, 513520.

27. Tartaglia, L.A., Storz, G., Farr, S.B. \& Ames, B.N. (1991). The bacterial adaptation to hydrogen peroxide stress. In Oxidative Stress. Oxidants and Antioxidants (ed. H. Sies), pp. 155-169. London: Academic Press.

28. Demple, B. (1991). Regulation of bacterial oxidative stress genes. Annual Review of Genetics 25, 315-337.

29. Aust, S.D. \& Svingen, B.A. (1982). The role of iron in enzymatic lipid peroxidation. In Free Radicals in Biology, Vol. 5 (ed. W.A. Prior), pp. 1-28. New York: Acadmic Press. 